\section{Sacl RFLPs at the D8S51 locus}

Bernhard Horsthemke*, Ruth Burdiek and HermannJosef Lüdecke

Institut für Humangenetik, Universitätsklinikum Essen, Hufelandstrasse 55, D-4300 Essen 1, FRG

Source/Description: L48 is a 150 bp single copy genomic DNA fragment cloned into pUC13. The clone was isolated by microdissection and microcloning of the Langer-Giedion syndrome chromosome region (LGCR).

Polymorphisms: SacI detects a two-allele polymorphism:

A1 $8.8 \mathrm{~kb}$

A2 $11.0 \mathrm{~kb}$

Frequencies: Estimated from 36 chromosomes

$\begin{array}{ll}\text { A1 } & 0.72 \\ \mathrm{~A} 2 & 0.28\end{array}$

Not Polymorphic For: AccI, AvaII, AspI, Asp700, BanI, BanII, BamHI, BclI, BglI, BglII, BstNI, BstXI, DraI, EcoRI, EcoRV, HindII, HindIII, HinfI, HgiAI, HpaI, KpnI, MspI, NciI, PstI, PvuII, RsaI, Sau96I, StuI, TaqI, XbaI in a screen of six unrelated Caucasian individuals.

Chromosomal Localization: Mapped to 8q23.2-q24.11 by quantitative Southern blot hybridization of DNA from patients with Langer-Giedion syndrome that have cytogenetically visible deletions.

Mendelian Inheritance: Autosomal codominant segregation was observed in two large Caucasian families.

Probe Availability: Available for collaboration: contact B.Horsthemke.

Other Comments: Insert can be released from the vector by EcoRI digestion.

Acknowledgements: Supported by the Deutsche Forschungsgemeinschaft.

Reference: Lüdecke et al. (1989) Nature 338, 348-350.

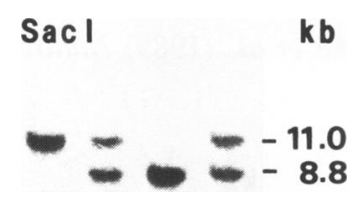

\section{Two polymorphisms in the non- coding regions of the $\mathrm{BCHE}$ gene}

\author{
C.F.Bartels ${ }^{\star}$, A.F.L.van der Spek ${ }^{1}$ and B.N.La Du
}

Departments of Pharmacology and ${ }^{1}$ Anesthesiology, University of Michigan Medical School, Ann Arbor, MI 48109-0626, USA

Source/Description: Exon 1 of the butyrylcholinesterase (BCHE) gene contains a polymorphic site at nt-116 (TGC/T스). Another polymorphism occurs at nt 1914 (A/G), 189 bases after the stop codon in exon 4 . The rarer $1914 \mathrm{G}$ creates an MaeII restriction site (1).

Frequencies: At nt -116 , the frequency of $\mathrm{G}$ is 0.92 and that of $A$ is 0.08 . At $n t 1914$ the frequency of $A$ is 0.74 and that of $G$ is 0.26 . Data are based on ds DNA sequencing of 33 unrelated, phenotypically usual, individuals. Numbers of heterozygous and homozygous individuals agree with the expected numbers from the Hardy-Weinberg equation.

Linkage: The above two polymorphisms appear to be in linkage disequilibrium: the less frequent $A$ at $n t-116$ always showed the less frequent $G$ at nt 1914 , although only one pedigree was examined to establish this coupling. The quantitative $\mathrm{K}$-variant BCHE mutation in exon 4, nt 1615 ( $\underline{G C A} \rightarrow \underline{A C A}$, $\mathrm{Ala} \rightarrow \mathrm{Thr}^{539}$ ), (frequencies of 0.87 and 0.13 ), is in linkage disequilibrium with the $G$ at nt 1914: 12 informative individuals exhibited this haplotype, and 11 other individuals were heterozygous at both sites. At nt -116 , the heterozygous G/A was always either heterozygous or homozygous for the $\mathrm{K}$-variant. $\chi^{2}$ tests indicate that the less frequent bases at these three sites are all in linkage disequilibrium. The point mutation causing the atypical $\mathrm{BChE}$ at Asp70 has been reported to be in linkage disequilibrium with the K-variant (88\%) (2).

Chromosomal Localization: Localized to 3q26.2 (P.McAlpine, personal communication).

Mendelian Inheritance: Both polymorphisms were examined in nine key members of a 50-person pedigree. Several other $\mathrm{BChE}$ variants (atypical, fluoride-resistant, J-variant, $\mathrm{K}$-variant) were present in this family so that linkage of the two polymorphisms with these established BCHE mutations could be examined.

Acknowledgement: NIH grant GM 27028, B.N.L.

References: 1)Arpagaus (1990) Biochem. 29, 124. 2) Bartels,C. et al. (1990) In Proceedings of the 3rd International Meeting on Cholinesterases. F.Bacou ed. ACS Books, Washington DC. In press.

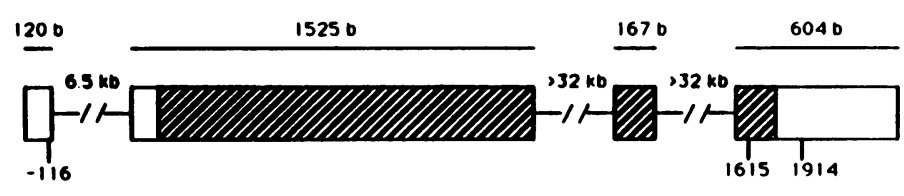

* To whom correspondence should be addressed 